and cigarette ash scattered indiscriminately, no matter how many ashtrays are provided.

\title{
Food poisoning
}

Statistics for the incidence of food poisoning are not yet available for Scotiand, as there was no legal obligation on the part of doctors to report these outbreaks until August 1956, when the Food and Drugs (Scotland) Act came into operation.

The last year for which there are complete statistics for England and Wales is I955. Family outbreaks are not included, because it is difficult to get sound information about them, but, in catering establishments, the number of outbreaks was 287 . Of these, rog occurred in school, works and services canteens, $3^{I}$ in institutions, 17 at private parties, 24 in restaurants and 37 were traced to shops, such as butchers, bakers, cooked-meat shops, grocers and dairies.

In 1953 , the figure for restaurants and clubs was 42 , and one hopes that this downward trend will continue.

In these and other incidents of food poisoning reported during the year, the number of patients involved was about 20,000, with $5 \mathrm{I}$ deaths. Much as one regrets even this number, it is small by comparison with the number of people who die from accidents at home (about 6600) and the 5000 who are killed each year on the roads.

\section{Clinical consequences of food poisoning as illustrated by a recent outbreak}

\section{By A. W. WRIGHT, Bangour Hospital, Broxburn, West Lothian, Scotland}

Food poisoning is the subject of some 200 or 300 publications in the medical press in each year, of which only a very small number deal with its clinical aspects. Its main interest to the hospital physician is in its influence as a complication on pre-existing disease and in the disruption of the hospital service which it may produce. It is believed that the symptoms are predominantly gastro-intestinal, that the diagnosis is always a simple matter, and that in any event the disease is fortunately self-limiting. Such optimism may be misplaced, for the early symptoms in the first cases in an outbreak may be quite misleading, and pyrexia and abdominal pain may precede by several hours the onset of diarrhoea and vomiting.

Furthermore, food poisoning may be a very severe disease in the young and in the aged, and mortality figures as high as $5 \%$ have been recorded, although $0.1 \%$ in the series of cases in the United States some years ago probably gives a better overall picture (Seligmann, Saphra \& Wassermann, I946). In addition, these infections are not uncommon in hospitals and other institutions, and their impact on a sick or infirm population may be disastrous.

The clinical features of the infection vary to some extent with the infecting organism. In staphylococcal food poisoning, for example, the symptoms come on suddenly and only 2 or $3 \mathrm{~h}$ after eating the contaminated food the patient is struck 
down with severe and continuous vomiting and diarrhoea, with a rise in temperature, and in many cases severe prostration. Usually these symptoms last for only a few hours, and provided the collapse and dehydration are corrected, the majority of patients recover rapidly within 24 or $48 \mathrm{~h}$.

A small proportion of cases, about $\mathrm{x} \%$ (Public Health Laboratory Service, I955) are due to Clostridium welchii infection and in these the symptoms are relatively mild, consisting of abdominal colic and diarrhoea, coming on after an incubation period of from io to $\mathrm{I} 8 \mathrm{~h}$. There is usually no rise in temperature and only occasionally vomiting. Only in the aged is this type of infection likely to have serious consequences.

By far the commonest form of food poisoning, and certainly of greatest clinical interest in this country, is that due to the salmonella organisms, and of these the Salmonella typhi-murium accounts for somewhere in the region of $80 \%$ (Public Health Laboratory Service, 1955). The incubation period is usually from 12 to $24 \mathrm{~h}$, but in a recent epidemic in my own experience it was, in some cases, considerably longer. Systemic disturbance is a striking feature in many, and headache, rise of temperature and occasionally rigors may occur some hours before the onset of diarrhoea and vomiting. In some, there may be persistent or spasmodic abdominal pain, and in the absence of diarrhoea this may give rise to errors in diagnosis.

The interest of these salmonella infections is in their tendency to spread beyond the gastro-intestinal tract, and the early symptoms suggest that a transient septicaemia may well be more common than is usually believed. In one series of 2000 cases in the United States, metastatic infections are reported in as many as $5^{\mathrm{I}}$ (Seligman et al. 1946). Firstly, abscesses may occur in relation to the alimentary tract, for example in mesenteric lymph nodes or in the abdominal wall, and meningitis, bacterial endocarditis, osteomyelitis and pyelitis are described. Probably the commonest organs to be infected are the lungs (Levine \& Plattner, r944) and the gall-bladder, and one case of longstanding salmonella lung infection was associated with an acid-fast saprophyte, which naturally gave rise to considerable difficulty in diagnosis (Kronenberger \& Smith, 1956). A genuine salmonella appendicitis may occur (Rubenstein \& Johnson, 1945). Lastly, various abscesses have been described in curious situations, such as the ribs, the thigh, the buttocks and, in one case, in the brain.

The following is a short account of an outbreak of food poisoning due to Salmonella typhi-murium which recently occurred in a general hospital. On the late afternoon of $5 \mathrm{July}$, ten patients were taken ill with headache, rise in temperature, abdominal pain and in some cases diarrhoea and vomiting. On the following day a further sixteen were affected and a further thirteen over the 4 succeeding days, so that the incubation period therefore varied from $24 \mathrm{~h}$ to 6 days. It soon became apparent that the outbreak was confined to those who had eaten a pork pie on the evening of 4 July.

The number of patients who actually ate the pie is not known exactly, but it is probably in the region of eighty. When the nature of the infection became known an investigation was carried out by the Public Health Authorities in the factory 
concerned and two girls were found to have Salmonella typhi-murium in the stools The girls were concerned with producing the gelatine which goes into the pie, and it was found that the facilities for the rapid cooling of the gelatine were unsatisfactory.

Of the people infected about $50 \%$ were in hospital for relatively minor procedures, such as herniotomy and tonsillectomy and were reasonably fit at the time of infection. Twenty, however, could be described as seriously ill. Four of these, for example, had a bronchogenic carcinoma with metastases, and six had severe cardiovascular disease, one a coronary thrombosis with multiple thrombo-embolic phenomena, and one an acute rheumatic carditis. Oddly enough, five had a fractured femur and this was, of course, a most unpleasant complication. Diarrhoea or vomiting was the first symptom in only sixteen, and the remainder had rigors, rise in temperature, headache, nausea and abdominal pain, some of them for several hours before the onset of the diarrhoea, the average length of time being $8 \mathrm{~h}$. A few cases had these constitutional symptoms for as long as $36 \mathrm{~h}$ before they developed diarrhoea. The average duration of the diarrhoea was just under 5 days, but it continued for 12 days in one or two cases. Three cases relapsed and had a further clinical attack after apparent recovery. Those whose primary illness was a severe one took no longer to get over their gastro-enteritis than the others, but there is no doubt that their convalescence was considerably delayed and in several the onset of this acute infection gave rise to considerable anxiety for a time. One young woman of 30 , for instance, had been in hospital for 3 months extremely ill with acute rheumatism, with a severe rheumatic carditis, with cardiac enlargement and failure. She was making reasonable progress, but 3 days after she ate the pie her temperature rose to $102^{\circ} \mathrm{F}$. and her pulse rate to 120 . She complained of diffuse lower abdominal pain and on the following day had eight loose bowel motions. She remained febrile for 9 days and it was I $_{4}$ days before her pulse rate returned to its previous level. Fortunately, thereafter she continued to recover.

One patient whose abdomen was opened was a hospital orderly suffering from an acute lumbar-disc lesion. On the day after eating the pie he complained of much more intense pain in his back and also in his lower abdomen. These symptoms increased and he developed marked lower abdominal rigidity and tenderness. On the following day he had some vomiting, and tenderness was now localized to the right iliac fossa. Laparotomy was duly carried out, at which the appendix was removed. Histologically it was found to be normal. The significant finding at operation was of marked oedema and congestion of the lower ileum and also quite appreciable enlargement of the mesenteric lymph glands. It was only on the following day, that is, $36 \mathrm{~h}$ after the onset of his lower abdominal pain, that he developed severe diarrhoea and he did in fact become dehydrated, requiring the parenteral administration of fluids.

In the treatment of these outbreaks, the majority of cases recover with rest in bed, adequate fluids being given by mouth or, where necessary, parenterally. Specific chemotherapy appears to have little influence in the course of the disease and the stools may remain positive for some weeks after the symptoms have subsided, in 
spite of such treatment. In this outbreak, thirty-two people received either succinylsulphathiazole, chloramphenicol or tetracyclines. Nine patients received no specific treatment and there is no evidence of any difference in the duration of symptoms in the two groups.

The organism eventually proved resistant to succinylsulphathiazole and sensitive to streptomycin, chloramphenicol and the tetracyclines, but by the time this information was available the majority of cases had recovered. It would be unwise to disregard the potential value of chemotherapy, however, particularly in view of the possibility of invasion of the blood stream with spread beyond the alimentary tract and there is some evidence that chloramphenicol is of value in this type of case (Hines, I95 I). It would therefore be wise to use either chloramphenicol or the tetracyclines as a routine measure in all these cases.

\title{
REFERENCES
}

Hines, A. (195 r). F. Amer, med. Ass, 147, 248.

Kronenberger, F. L. \& Smith, H. C. (1956). Brit. F. Tuberc. 50, 225.

Levine, M. G. \& Plattner, E. B. (I944). Amer. F. clin. Path. 14, 342.

Public Health Laboratory Service (1955). Mon. Bull. Minist. Hlth Lab. Serv. 14, 203.

Rubenstein, A. D. \& Johnson, B. B. (1945). Amer. F. med. Sci. 210, 5 I7.

Seligmann, E., Saphra, I. \& Wassermann, M. (1946). F. Immunol. 54, 69.

\section{Protecting food at home and in the canteen}

\author{
By Lucy C. Currie, Glasgow and West of Scotland College of Domestic Science, \\ I Park Drive, Glasgow, C.3
}

To prepare housewives and canteen workers for what is, truly, an unremitting battle, we must continue to pinpoint for them: ( $I$ ) the foods most vulnerable to bacterial contamination such as manipulated meats and reheated dishes; (2) the channels through which any food may be attacked; (3) simple practical ways of preventing contamination. Infestation by non-bacterial agents, e.g. weevils, is of less importance, because contamination is more obvious. Care must be taken to destroy the pests before the food is discarded, to prevent further spread of infestation.

Good work towards education in food hygiene has been, and is being, done by well-tried propaganda methods: this must be continued, and interpreted in a practical way, in homes by health visitors, and in canteens by manageresses.

Before staff in canteens is willing to learn and undertake the necessary discipline of food handling, conditions must encourage good teamwork. The following practical aids, some of which are embodied in the new Food and Drugs Act, should be considered (I) proper delegation of duties and responsibilities; (2) attractive, sufficient, effective uniform; (3) good cloakroom and toilet accommodation; (4) efficient working conditions; (5) attention to health; here, unfortunately compromise is too often necessary with cases of minor illness. 